\title{
ANALISIS KESALAHAN PENYUSUNAN RENCANA PELAKSANAAN PEMBELAJARAN MAHASISWA PROGRAM PENDIDIKAN PROFESI GURU
}

\author{
Erlita Agustina ${ }^{1}$, Jumadi ${ }^{2}$ \\ ${ }^{1,2}$ Pendidikan Fisika, Program Pascasarjana, Universitas Negeri Yogyakarta
}

\begin{abstract}
Teacher Professional Education provides an assessment of the lesson plan made by students as a component in teacher competency testing. A good lesson plan results will help the teacher in directing the learning process in the classroom.

The lesson plan is one of the supporting components in the assessment of Professional Teacher Education. The purpose of this study is to describe the results of the analysis of the lesson plan that has been made by the Teacher Professional Education of Physics Education students. This research is qualitative research with descriptive method. The study was conducted in December 2019 in Yogyakarta. The results of this study indicate that Teacher Professional Education of Physics Education student has been able to prepare lesson plans well according to the assessment aspects. However, there are some errors in its preparation. These errors are (1) learning indicators that are not following the basic competencies to be achieved, and learning objectives do not all contain ABCD (Audience, Behavior, Condition, and Degree) or CABD (Condition, Audience, Behavior, and, Degree), (2) The evaluation instrument used is not appropriate because there are no instruments for the plan of enrichment activities for students who have more abilities and plans for remedial activities for students who have fewer abilities.
\end{abstract}

Keywords: Lesson plan, Teacher Professional Education

\begin{abstract}
Abstrak
Pendidikan Profesi Guru (PPG) memberikan penilaian terhadap RPP yang dibuat oleh mahasiswa sebagai salah satu komponen dalam pengujian kompetensi guru. Hasil RPP yang baik akan membantu guru dalam mengarahkan proses pembelajaran di kelas.

RPP merupakan salah satu komponen penunjang dalam penilaian di Pendidikan Profesi Guru. Tujuan dari penelitian ini adalah untuk mendeskripsikan hasil analisis dari RPP yang telah dibuat oleh mahasiswa PPG Pendidikan Fisika. Penelitian ini merupakan penelitian kualitatif dengan metode deskriptif. Penelitian dilakukan pada bulan Desember 2019 di Yogyakarta. Hasil penelitian ini menunjukkan bahwa mahasiswa PPG Pendidikan Fisika telah dapat menyusun RPP dengan baik sesuai dengan aspek penilaian. Namun, terdapat beberapa kesalahan dalam penyusunannya.
\end{abstract}

Pascasarjana Universitas Negeri Yogyakarta

Email: erlitaagustina23@gmail.com
C2020 Universitas Islam Negeri Walisongo 142

ISSN: 2088-7868, e-ISSN 2502-5708 
Kesalahan tersebut yaitu (1) indikator pembelajaran belum sesuai dengan kompetensi dasar yang akan dicapai, dan tujuan pembelajaran belum seluruhnya memuat $\mathrm{ABCD}$ (Audience, Behavior, Condition, and Degree) atau CABD (Condition, Audience, Behavior, and Degree), (2) instumen evaluasi yang digunakan belum sesuai karena tidak terdapat instrumen untuk rencana kegiatan pengayaan bagi siswa yang memiliki kemampuan lebih dan rencana kegiatan remedial bagi siswa yang memiliki kemampuan kurang.

Kata kunci: Rencana Pelaksanaan Pembelajaran, PPG.

\section{PENDAHULUAN}

Pendidikan memiliki peran penting untuk membentuk masa depan bangsa dan diharapkan dapat membentuk sumber daya manusia yang profesional. Predikat profesional disematkan kepada orang yang telah mempunyai kompetensi dan keahlian yang didapat melalui berbagai program pendidikan tertentu secara berkelanjutan dan tetap menaati kode etik profesi suatu pekerjaan (Prasetyo, 2018). Guru merupakan jabatan profesional yang mengharuskan guru untuk memiliki kualifikasi akademik, kompetensi, sertifikat pendidik, sehat secara jasmani-rohani, dan mampu untuk mendukung tujuan pendidikan nasional. Profesi sebagai guru tidak bisa disandang oleh sembarang orang tanpa pendidikan, pelatihan, dan persiapan (Galih, 2018).

Mengingat pentingnya peran seorang guru untuk meningkatkan kualitas pendidikan Indonesia, maka guru perlu dipersiapkan dengan sedemikian rupa untuk menjadi guru yang profesional, salah satu caranya adalah mengikuti PPG. Salah satu upaya pemerintah untuk memenuhi kebutuhan guru profesional dilakukan dengan memperketat sistem rekrutmen guru. Pemenrintah daerah tidak diijinkan untuk merekrut guru honorer khususnya bagi sekolah negeri. Saat ini emerintah lebih mengutamakan perekrutan guru melalui program Calon Pegawai Negeri Sipil (CPNS) dan Pegawai Pemerintah dengan Perjanjian Kerja (PPPK) dengan menggunakan sistem rekrutmen yang profesional (Arifa \& Prayitno, 2019).

Pemerintah banyak berperan dalam memfasilitasi kegiatan untuk membentuk tenaga pengajar yang profesional. Program yang diadakan pemerintah baru-baru ini adalah program pendidikan dan Latihan Profesi Guru (PLPG) bagi tenaga pengajar dalam jabatan dan dilanjutkan dengan Program Profesional Guru (PPG) untuk guru pra-jabatan (Prasojo, Wibowo, \& Hastutiningsih, 2017). PPG merupakan suatu program yang dinilai dapat menghadirkan calon-calon pendidik profesional yang siap mengabdi dan 
meningkatkan kualitas pendidikan Indonesia. PPG bertujuan untuk menghasilkan calon guru yang berkompeten dalam merencanakan, melaksanakan, menilai pembelajaran, menindaklanjuti hasil penilaian, melakukan pembimbingan dan latihan pada siswa, serta melakukan penelitian, dan mampu mengembangan profesionalitas secara berkelanjutan (Prasetyo, 2018)

Kualitas suatu pendidikan hanya dapat diupayakan oleh guru yang profesional. Guru profesional mempunyai empat kompetensi yang terdiri dari kompetensi pedagogik, kompetensi kepribadian, kompetensi sosial, dan kompetensi profesional (Ridwan, Alben Ambarita, n.d.). Pengetahuan guru merupakan dasar untuk mencapai kompetensi pedagogik. Kompetensi pedagogik guru terdiri dari kepemilikan dokumen, kemampuan merencanakan pembelajaran, dan kemampuan melaksanakan pembelajaran (Ridwan, Alben Ambarita, n.d.).

Pendidikan di Indonesia telah beberapa kali mengalami perubahan kurikulum. Perubahan ini dibuat agar pendidikan di Indonesia dapat mengikuti perkembangan zaman Kurikulum 2013 saat ini digunakan dalam pembelajaran di Indonesia. Rencana Pelaksanaan Pembelajaran (RPP) yang dibuat juga harus menyesuaikan dengan Kurikulum 2013. RPP merupakan rancangan pembelajaran per unit dari mata pelajaran yang akan digunakan oleh guru untuk pembelajaran di kelas. Adanya RPP diharapkan dapat membantu guru untuk menciptakan pembelajaran yang lebih terorganisir. Sebuah RPP sudah selayaknya meiliki kemampuan untuk dapat diterapkan dengan baik. Tanpa adanya perencanaan yang matang, tujuan pembelajaran akan sulit dicapai dengan maksimal. Oleh karena itu, kemampuan membuat RPP merupakan syarat awal bagi guru dan calon guru (Setyawanto, Sunaryo, \& Basuki, 2012).

Pada dasarnya penyusunan RPP memiliki tujuan untuk dapat merancang pengalaman belajar peserta didik untuk mencapai tujuan pembelajaran (Setyawanto et al., 2012). Hasil evaluasi terhadap implementasi kurikulum 2013 di sekolah secara nasional telah memperlihatkan bahwa sebagian besar sekolah masih belum siap menggunakannya dalam pembelajaran (Marwan, 2015). Selain kesiapan guru dalam mengajar, kesuksesan proses belajar mengajar juga dapat dipengaruhi oleh kerjasama antara guru dan peserta didik. Tetapi, memang pada mulanya guru yang pertama menentukan kesuksesan pembelajaran. Awal mula kelancaran pembelajaran dimulai dengan rencana guru untuk melaksanakan pembelajaran di kelas. Rencana ini tertuang dalam perangkat pembelajaran 
dalam bentuk RPP (Zendrato, 20016).

RPP merupakan salah satu dari dokumen yang harus dimiliki guru. Setiap guru maupun calon guru dituntut untuk cakap dalam menyusun RPP. Tetapi, para guru belum sepenuhnya mampu menyusun RPP dengan baik. banyak guru yang hanya meng-copy paste RPP dari internet tanpa merevisinya lagi. (Bangun, 2018). Beberapa guru melakukan kegiatan belajar mengajar kurang sesuai dengan RPP yang telah dibuat, bahkan ada yang tidak menggunakan RPP dalam melaksanakan pembelajaran. Yang sangat fatal adalah guru yang mengajar tidak berdasarkan RPP tetapi mengajar sesuai dengan selera sendiri (Asmawati, 2017).

Beberapa penyebab guru belum dapat menyusun RPP dengan baik karena guru belum dapat merumuskan indikator dan tujuan pembelajaran, belum sesuainya materi pelajaran dengan tujuan pembelajaran, guru belum memahami kompetensi dasar secara keseluruhan, belum mampu mengidentifikasi materi apa saja yang terkandung dalam kompetensi dasar, seberapa luas dan dalamnya materi yang harus diberikan, keterampilan apa yang harus dimiliki peserta didik agar mencapai kompetensinya, bagaimana peserta didik dapat menguasai keterampilan yang sesuai dengan tujuan pembelajaran, indikator apa yang dapat menunjukkan bahwa peserta didik telah mencapai kompetensinya, berapa lama waktu yang diperlukan untuk pembelajaran pada kompetensi dasar tersebut, media/sumber belajar apa yang diperlukan untuk membantu peserta didik mencapai kompetensinya, instrumen apa yang harus digunakan agar tepat dalam mengukur ketercapaian kompetensi yang diinginkan (Ridwan, Alben Ambarita, n.d.).

Pemilihan model dan metode belum sesuai dengan perkembangan abad 21. Langkah-langkah pembelajaran umumnya tidak mengacu pada metode pembelajaran yang digunakan (Makhrus, 2018). Selain itu guru juga mengalami beberapa masalah dalam penyusunan RPP (Zendrato, 20016): (1) Guru memiliki jumlah jam mengajar yang tinggi sehingga RPP seringkali tidak tersiapkan sebelum mengajar, (2) Guru menulis RPP karena tuntutan administrasi sekolah. Oleh karena itu, faktor-faktor yang mempengaruhi pelaksanaannya di kelas kurang diperhatikan, (3) Guru berpendapat bahwa adanya RPP tidak menjamin tujuan pembelajaran akan tercapai, (4) Guru memiliki pemahaman bahwa RPP tidak selalu dapat diterapkan di kelas (5) Guru merasa enggan untuk menjabarkan RPP secara detil mengingat banyak komponen yang harus ditulis untuk satu kali pembelajaran. 
Hal-hal pokok yang terdapat dalam RPP meliputi (1) tujuan pembelajaran yang hendak dicapai, (2) bahan ajar yang perlu dikuasai siswa, (3) bentuk pengalaman atau kegiatan seperti apa yang perlu dialami siswa untuk menguasai kompetensi tertentu, (4) bagaimana dan cara apa yang tepat untuk menilai ketercapaian tujuan pembelajaran, dan (5) alokasi waktu pelaksanaan pembelajaran yang efektif. Oleh karena itu, guru professional wajib mampu menyusun RPP dengan minimal memperhatikan lima alasan di atas mengapa penting disusunnya kurikulum (Dewi \& Krismawati, 2018)

Setelah mengikuti PPG, pendidik diharapkan dapat menyusun RPP yang sesuai dengan kurikulum dengan baik dan benar. Penelitian ini bertujuan untuk mendeskripsikan hasil analisis kesalahan yang masih terjadi pada mahasiswa PPG Pendidikan Fisika dalam menyusun RPP.

\section{METODE PENELITIAN}

Penelitian ini merupakan penelitian kualitatif deskriptif. Peneliti akan mendeskripsikan secara rinci tentang hasil penelitian. Data yang dideskripsikan berupa kesalahan menyusun RPP pada mata pelajaran fisika mahasiswa PPG. Berdasarkan hal tersebut, maka penelitian ini dapat disebut dengan penelitian deskriptif (Dewi \& Krismawati, 2018)

Peneliti menganalisis kesalahan penyusunan RPP yang disusun oleh mahasiswa PPG Pendidikan Fisika pada bulan Desember 2019 yang bertempat di Yogyakarta. Subjek dari penelitian ini adalah RPP dari mahasiswa PPG pada program studi Pendidikan Fisika. Teknik pengumpulan data penelitian dilakukan melalui dua tahapan. Pertama, tahap pengumpulan RPP melalui responden. Tahap kedua berupa penilaian RPP berdasarkan kelengkapan dan kesesuian komponen RPP dengan tuntutan kurikulum 2013. Data yang didapatkan melalui penelitian ini berupa data kualitatif. Data kualitatif, didapatkan melalui analisis kesalahan yang ditemukan dalam RPP yang telah disusun oleh mahasiswa. Analisis RPP dilakukan dengan kesesuaian komponen pada RPP dengan aspek-aspek penilaian RPP pada penelitian ini. Aspek-aspek penilaian ditunjukkan pada Tabel 1. 
Tabel 1. Aspek Penilaian RPP

\begin{tabular}{cl}
\hline No. & \multicolumn{1}{c}{ Aspek Penilaian RPP } \\
\hline 1 & $\begin{array}{l}\text { Perumusan dan penyesuaian pengembangan kompetensi dasar, tujuan } \\
\text { pembelajaran, dan indikator pencapaian kompetensi }\end{array}$ \\
2 & Pemilihan dan pengembangan materi pembelajaran \\
3 & Pemilihan dan kelengkapan Metode, model, pendekatan pembelajaran yang \\
& digunakan \\
4 & Pemilihan Media pembelajaran yang digunakan \\
5 & Pemilihan sumber belajar dalam pembelajaran \\
6 & Penyusunan kegiatan/langkah pembelajaran sesuai sintaks \\
7 & Penggunaan instrumen evaluasi pembelajaran \\
\hline
\end{tabular}

\section{HASIL DAN PEMBAHASAN}

Hasil dari penilaian terhadap RPP mahasiswa PPG Pendidikan Fisika yang dijadikan sampel dalam penelitian ini tidak menunjukkan banyak kesalahan. Penyebab sedikitnya kesalahan yang terdapat pada RPP mahasiswa PPG Pendidikan Fisika adalah mahasiswa sudah memiliki bekal yang cukup dalam penyusunan RPP mulai dari kuliah strata satu dan pembekalan selama kuliah PPG. Hal positif ini diharapkan dapat tetap dipertahankan sampai proses pembelajaran disekolah.

Berdasarkan hasil analisis RPP, ditemukan data-data yang sesuai dengan aspek penilaian RPP. Data yang sesuai dengan aspek penilaian yaitu pertama, pada aspek pemilihan dan pengembangan materi. Pemilihan dan pengembangan materi telah sesuai dengan tujuan pembelajaran, indikator, dan kompetensi dasar yang akan dicapai. Materi pembelajaran yang digunakan juga telah memuat fakta, konsep, prinsip dan prosedur yang relevan secara lengkap. Kedua, pada aspke pemilihan metode, model dan pendekatan pembelajaran telah dituliskan secara lemgkap, sesuai dengan materi pelajaran, dan mampu mendukung kecakapan berpikir peserta didik. Ketiga, media pembelajaran yang digunakan dapat menyesusaikan dengan tujuan kurikulum 2013. Media pembelajaran menerapkan teknologi informasi dan komunikasi yang sesuai dengan tujuan, materi, kondisi kelas, dan memperhatikan keselamatan. Materi yang dikembangkan sesuai dan dapat mendukung tercapainya peningkatan kemampuan berpikir peserta didik dari LOTS menuju HOTS. Keempat, pemilihan sumber belajar telah sesuai dengan tujuan pembelajaran serta memperhatikan relevansi dan kemutakhiran. Kelima, langkah pembelajaran yang digunakan telah sesuai dengan sintaks 
pembelajaran. Langkah-langkah kegiatan pembelajaran dicantumkan secara jelas pada kegiatan awal, inti, dan penutup telah disertai dengan alokasi waktu. Rumusan langkahlangkah kegiatan pembelajaran memuat kemampuan yang mendukung pengembangan kemampuan berpikir tingkat tinggi (HOTS), pengembangan karakter, dan kemampuan literasi peserta didik, dan menerapkan pembelajaran yang aktif. Langkah-langkah pembelajaran yang sesuai dengan metode pembelajaran disusun secara runtut dan sesuai dengan tujuan pembelajaran yang akan dicapai.

Penyebab sedikitnya kesalahan yang terdapat pada RPP mahasiswa PPG Pendidikan Fisika adalah mahasiswa sudah memiliki bekal yang cukup dalam penyusunan RPP mulai dari kuliah strata satu dan pembekalan selama kuliah PPG. Hal positif ini diharapkan dapat tetap dipertahankan sampai proses pembelajaran disekolah. Namun masih terdapat beberapa kesalahan dalam penyusunan RPP mahasiswa PPG Pendidikan Fisika. Kesalahan tersebut terdapat pada beebrapa aspek yaitu pertama, kesesuaian perumusan dan pengembangan pada kompetensi dasar, tujuan pembelajaran, dan indikator pencapaian kompetensi. Indikator pembelajaran belum sesuai dengan kompetensi dasar yang akan dicapai, dan tujuan pembelajaran belum seluruhnya memuat ABCD (Audience, Behavior, Condition, and Degree) atau CABD (Condition, Audience, Behavior, and Degree). Tujuan, indikator, dan kompetensi dasar merupakan komponen yang saling berkesinambungan. Bila pada tujuan pembelajaran tidak lengkap guru akan kesulitan dalam menilai pembelajaran. Indikator pembelajaran yang tidak sesuai dengan kompetensi dasar tidak dapat mencapai kompetensi dengan sempurna. Kedua, instumen evaluasi yang digunakan belum sesuai karena tidak terdapat instrumen untuk rencana kegiatan pengayaan bagi siswa yang memiliki kemampuan lebih dan rencana kegiatan remedial bagi siswa yang memiliki kemampuan kurang.

Kesalahan tersebut disebabkan karena kurang cermat dalam merumuskan indikator dan tujuan pembelajaran, serta belum terdapatnya rencana dalam melakukan kegiatan pengayaan maupun remidial untuk peserta didik.

\section{SIMPULAN}

Secara umum setelah dilakukan analisis pada RPP mahasiswa PPG Pendidikan Fisika terdapat kesesuian RPP dengan indikator analisis. Tetapi, ditemukan beberapa kesalahan dalam penyusunan RPP. Kesalahan tersebut yaitu (1) indikator pembelajaran 
belum sesuai dengan kompetensi dasar yang akan dicapai, dan tujuan pembelajaran belum seluruhnya memuat $\mathrm{ABCD}$ (Audience, Behavior, Condition, and Degree) atau CABD (Condition, Audience, Behavior, and Degree), (2) instumen evaluasi yang digunakan belum sesuai karena tidak terdapat instrumen untuk rencana kegiatan pengayaan bagi siswa yang memiliki kemampuan lebih dan rencana kegiatan remedial bagi siswa yang memiliki kemampuan kurang. Setelah adanya hasil dari penelitian ini diharapkan kedepannya terdapat pendampingan dalam penyusunan setiap komponen RPP dan mahasiswa PPG lebih cermat dalam menyusun RPP agar dapat diterapkan dengan baik saat pembelajaran.

\section{DAFTAR PUSTAKA}

Arifa, F. N., \& Prayitno, U. S. (2019). Peningkatan Kualitas Pendidikan: Program Pendidikan Profesi Guru Prajabatan dalam Pemenuhan Kebutuhan Guru Profesional di Indonesia. Jurnal Aspirasi, 10(1), 1-17. https://doi.org/10.22212/aspirasi.v10i1.1229

Asmawati. (2017). Meminimalkan Kesalahan Guru Kelas dalam Penyusunan Rencana Pelaksanaan Pembelajaran (RPP) Melalui Pendampingan Berbasis KKG Semester Dua Tahun Pelajaran 2016/2017 Di SD Negeri 18 Mataram. JIME, 3(1), 1-14.

Bangun, T. A. (2018). Analisis Kesesuaian Antara Komponen Rpp Bahasa Indonesia Kelas Vii Di Smp Negeri 14 Langsa Dan Kurikulum 2013. Edukasi Kultura : Jurnal Bahasa, Sastra Dan Budaya, 1(1), 1-20. https://doi.org/10.24114/kultura.v1i1.11697

Dewi, R. P., \& Krismawati, S. (2018). Kemampuan menyusun perangkat rencana pelaksanaan pembelajaran mahasiswa program studi pendidikan bahasa dan sastra indonesia angkatan 2014 tahun akademik 2016/2017. 633, 633-648.

Galih, A. (2018). Persepsi Mahasiswa Program Pendidikan Profesi Guru (PPG) Pendidikan Sejarah Terhadap Program PPG. Jurnal Pendidikan Sejarah, 7(1), 6683. https://doi.org/10.21009/jps.071.05

Makhrus, M. (2018). Analisis Rencana Pelaksanaan Pembelajaran (Rpp) Terhadap Kesiapan Guru Sebagai "Role Model” Keterampilan Abad 21 Pada Pembelajaran Ipa Smp. Jurnal Penelitian Pendidikan IPA, 5(1). https://doi.org/10.29303/jppipa.v5i1.171

Marwan, L. (2015). Upaya meningkatkan kompetensi guru ipa dalam penyusunan rpp berdasarkan ktsp melalui pendampingan berbasis mgmp semester genap tahun pelajaran 2014/2015 di smp negeri 8 mataram.

Prasetyo, Z. K. (2018). Penyiapan Guru Profesional Melalui Program Profesi Guru. 25. 
Prasojo, L. D., Wibowo, U. B., \& Hastutiningsih, A. D. (2017). Manajemen Kurikulum Program Profesi Guru Untuk Daerah Terdepan, Terluar, Dan Tertinggal Di Universitas Negeri Yogyakarta. Jurnal Pendidikan Dan Kebudayaan, 2(1), 39. https://doi.org/10.24832/jpnk.v2i1.538

Ridwan, Alben Ambarita, I. S. (n.d.). Manajemen Peningkatan Kompetensi Pedagogik Guru Melalui Pendampingan Pendekatan Kolaboratif. (1).

Setyawanto, A., Sunaryo, H. ., \& Basuki, I. A. (2012). Rencana Pelaksanaan Pembelajaran (RPP) Guru Bahasa Indonesia Tingkat SMP di Kota Malang. Jurnal Rencana Pembelajaran, 1(3), 1-11.

Zendrato, J. (20016). Studi Kasus di SMA Dian Harapan Jakarta Juniriang Zendrato FIP - Universitas Pelita Harapan ABSTRAK. E-JurnalUKSW, 58-73. 